\title{
LA CORRESPONDENCIA COMO FUENTE DOCUMENTAL PARA LA EMIGRACIÓN A VENEZUELA EN EL ARCHIVO GENERAL DE LA ADMINISTRACIÓN (1959-1960)
}

\author{
Nazaret Martín Pérez
}

\section{RESUMEN}

A mediados del siglo xx, los españoles atravesaban un período de dificultad, marcado por el contexto internacional y nacional. La emigración, en este caso a Venezuela, se les planteó como una alternativa a esta realidad. El presente artículo tiene como objetivo mostrar todas las vías que puede ofrecer la correspondencia, la cual es un legado histórico documental, para historiar la vida cotidiana y de la familia desde una perspectiva de la emigración.

PALABRAS ClAVE: correspondencia, documentación, emigración, Venezuela, estudios de género, Archivo General de la Administración.

\author{
CORRESPONDENCE AS A DOCUMENTARY SOURCE \\ FOR THE EMIGRATION TO VENEZUELA IN ARCHIVO \\ GENERAL DE LA ADMINISTRACIÓN (1959-1960)
}

\section{Abstract}

In the middle of the 20th century, the Spanish people were going through a period of difficulty, marked by the international and national context. Emigration to Venezuela was presented as a serious alternative to this reality. This paper wants to show all the channels that correspondence can offer, which is a documentary historical legacy to record daily and family life, from an emigration perspective.

KeYwORDs: correspondence, documentation, emigration, Venezuela, gender studies, Archivo General de la Administración. 


\section{INTRODUCCIÓN}

Los historiadores nos debemos al estudio de las fuentes primarias, y la correspondencia, ya sea de carácter público o privado, es un elemento documental clave como tal, a través del cual se puede y debe historiar el pasado. En este caso, la temática que se aborda es la emigracion española a Venezuela (1959-1960), y la documentación que se analiza es el legado documental que un proceso emigratorio deja tras de sí.

El enfoque principal de este artículo es por tanto de carácter documental, sin obviar su naturaleza indisolublemente histórica; pues el objetivo principal es ver cómo a través de la correspondencia, podemos historiar lo que en la historiografía se ha denominado como historia de la vida cotidiana. El caso que nos ocupa estará enmarcado en el contexto histórico de la emigración a Venezuela en las décadas centrales del siglo xx. Esta documentación epistolar constituye un legado documental, que nos permite adentrarnos en las repercusiones de la emigración en el ámbito familiar y/o social, a través de un marcado carácter personal.

Antes de adentrarnos en profundidad en la temática que nos ocupa, es necesario aclarar el contexto histórico en el que se produce la emigración española a Venezuela. Teniendo en cuenta que la realidad en Espańa durante la mayor parte de la contemporaneidad ha sido bastante precaria, los diversos territorios del continente americano fueron una alternativa a la situación de dificultad que los emigrantes vivían en su lugar de origen. Este proceso migratorio, como hemos comentado anteriormente, fue una alternativa a la realidad que se vivía en Espańa durante el siglo xx, que es el segmento temporal que atañe a esta investigación. La emigración suponía una elección común para poner fin (o al menos mitigar) la situación de dificultad que los españoles vivían en su lugar de origen, debido a las consecuencias del contexto internacional pero, sobre todo, nacional, heredera de la Guerra Civil y del franquismo ${ }^{1}$. Venezuela, por contra, era un país atrayente pues estaba en pleno proceso de crecimiento económico y modernización a mediados de la centuria, y además, había iniciado una política migratoria «de puertas abiertas»" Debido a esta expansión económica y a su escasa mano de obra, el país se convertía en un elemento demandante de brazos para el trabajo, una oferta laboral que ocuparon trabajadores europeos, españoles y canarios.

Este artículo busca aportar un granito de arena más a la ampliamente trabajada emigración española a Venezuela, de la que siempre quedan segmentos por estudiar. Es, por tanto, un trabajo a mbivalente y que se compone a través de la documentación situada en archivos nacionales, en este caso, en el Archivo General de la Administración, cuya finalidad principal es mostrar la capacidad y potencialidad

${ }_{1}$ Sánchez Marroyo, Fernando: La España del siglo XX. Economía, demografía y sociedad, Madrid: Istmo, 2003.

${ }^{2}$ Quintero Montiel, Inés: «El siglo xx: conquista, construcción y defensa de la democracia», en Pino Iturrieta, Elías (coord.): Historia Minima de Venezuela, Madrid, México D.F.: Turner. El Colegio de México, 2018, pp. 182-183. 
que tiene la correspondencia a la hora de historiar un proceso histórico. Siguiendo humildemente la estela de Ginzburg en la búsqueda de eludir lo que él denominó «la persistencia difusa de una concepción aristocrática de la cultura»" el presente artículo se basará en dos premisas principales. Por un lado, se realizará una cata sobre ciertas informaciones cuantitativas que están recogidas en la profusión de datos que muchas de estas cartas, en principio poco propicias para estos estudios, muestran. Por otro, se analizarán las diferentes potencialidades que esta documentación posee a la hora de historiar cuestiones relativas a la vida cotidiana y/o familiar. Este estudio presenta una confluencia de lo cuantitativo con lo cualitativo, con una metodología que se adapta a las necesidades de la documentación y, sobre todo, al ámbito de estudio concreto en el que se enfoca en cada momento.

La decisión de situar la cata en este bienio no es arbitraria, sino que responde a una cuestión contextual. Con la década de los cincuenta finaliza el período de auge del fenómeno migratorio hispano-venezolano. La crisis económica que experimentará el país caribeño, el cambio de régimen que se produce en el mismo, así como el paso de una política migratoria de puertas abiertas a otra más reestrictiva en 19614, marcan un cambio significativo en la tendencia migratoria entre España y Venezuela.

Se hace necesario, además, tener en cuenta que el hecho de que el estudio cuantitativo muestre una serie de datos no significa que estos sean extrapolables a la totalidad del proceso migratorio. Estos son datos extraídos para una cuestión concreta. Es más, la primacía de los contingentes canario y gallego en este proceso migratorio no queda en entredicho, sino que los documentos nos muestran una vía de comunicación diferente entre las dos orillas.

\section{UNA REVISIÓN CUANTITATIVA}

En este primer apartado vamos a realizar una cata sobre la información que podemos encontrar en el Archivo General de la Administración (Alcalá de Henares) para los años 1959-1960. Esta documentación corresponde a los fondos documentales generados por la Embajada de España en Caracas, la cual pertenecía al antiguo archivo del Ministerio de Asuntos Exteriores, y que posteriormente fueron trasladados al Archivo General de la Administración.

Dicha documentación nos deja un saldo muestral de casi una veintena de documentos, que se encuentran entrelazados, insertos y mezclados entre los varios centenares de documentos con los que comparten ubicación y legajos en los fondos del archivo.

3 Ginzburg, Carlo: El queso y los gusanos. El cosmos según un molinero del siglo XVI, Barcelona: Ediciones Península, 1999, p. 15.

${ }^{4}$ Margolies, Luise: «Dictaduras y política migratoria. El caso de Venezuela en la década de los cincuenta", en Morales Padrón, Francisco (coord.): XI Coloquios de Historia Canario-americana, Las Palmas de Gran Canaria: Casa de Colón. Cabildo de Gran Canaria, 1994, pp. 392-397. 


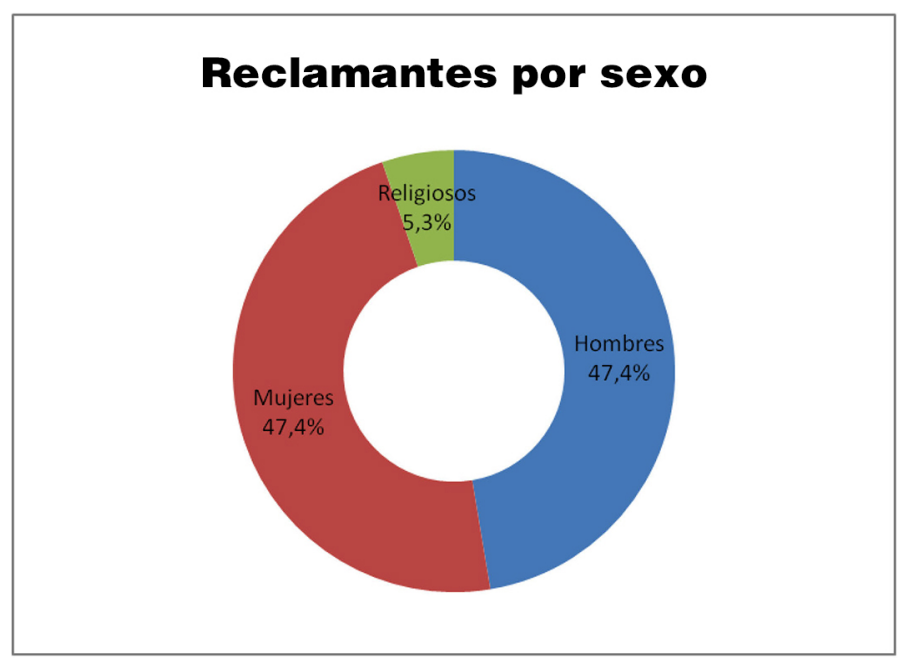

Figura 1. «Reclamantes por sexo». Elaboración propia.

En este primer segmento, vamos a analizar la correspondencia que recibía esta Embajada por parte de los familiares o allegados de estos emigrantes que recurrían a la dicha institución para poder obtener noticias de sus parientes emigrados en Venezuela y que, por una razón u otra, han perdido el contacto con ellos. Aunque en este estudio nos vamos a centrar entre finales de 1959 y el año de 1960 podríamos estudiar otra cronología, a través de los fondos documentales que se encuentren en este Archivo.

Como se observa en la figura 1, podemos ver una proporción prácticamente igualitaria con respecto al sexo desde quienes reclaman información desde el país de origen. Este dato podría parecer curioso debido a las condiciones del contexto español en ese momento, por ello resulta necesario realizar una aclaración previa. Cuando se habla de reclamantes, se identifica al interlocutor que aparece mencionado en las cartas y no al interesado en última instancia. Esto es relevante debido a que una cantidad nada insignificante de los interlocutores que aparecen en las mismas no sean los mismos que los interesados últimos, variando de manera considerable unos datos que podrían estar más adaptados a una realidad diferente. Se deben tener en cuenta dos factores contextuales para entender dicha cuestión, por un lado, no se puede obviar el segundo plano legal al que el franquismo reducía a las mujeres 5 , por lo que se puede estimar que haya algo de sobrerrepresentación masculina; y por otro, tampoco se pueden obviar los altos niveles de analfabetismo

5 Ruiz Franco, Rosario: ¿Eternas menores? Las mujeres en el franquismo, Madrid: Biblioteca Nueva, 2007. 


\section{Reclamados por sexo}

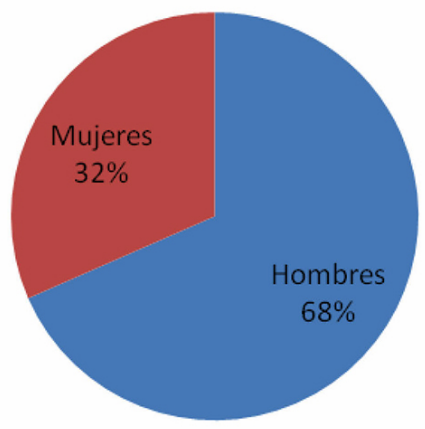

Figura 2. «Reclamados por sexo». Elaboración propia.

que la España de aquel entonces padecía ${ }^{6}$ (y de arbitrariedad en la administración) haciendo que muchas de las reclamaciones fueran intercedidas por otros actores que tuvieran más capacidad de influencia en la administración por su empleo o posición social. Como evidencia de ello, vemos que unas cartas están manuscritas y otras mecanografriadas, y presentan diferentes modos de redacción (con faltas de ortografía ausentes o presentes).

En el segundo de los gráficos, que recibe el nombre de figura 2, a diferencia del gráfico anterior, sí que se puede observar una diferencia de género importante. Más de dos de cada tres reclamados en nuestra muestra son hombres. Esta mayoría encaja perfectamente en los datos sociales generales para el período, en los que la mayor parte de la emigración era de hombres solteros?. Aun así, esto nos habla de una profunda emigración de mujeres solas, las cuales no era extraño que realizaran viajes de esta tipología.

En cuanto a la relación que se expresa entre el reclamante y el reclamado, nos encontramos con dos tipos de parentesco que se imponen por encima del resto.

${ }^{6}$ En el año 1960, las tasas de analfabetismo en España se situaban en el 17\% para los hombres y el 23\% para las mujeres. Datos extraídos de Vilanova Ribas, Mercedes; Moreno Julià, Xavier: Atlas de la evolución del analfabetismo en España de 1887 a 1891, Madrid: Ministerio de Educación y Ciencia, 1992, p. 170.

7 Durante los ańos cuarenta y cincuenta del siglo xx, la emigración joven a América supuso la mayor parte del contingente. Entre esa emigración joven seguía existiendo amplia mayoría de hombres. Véase Palazón Ferrando, Salvador: Capital humano español y desarrollo económico latinoamericano: evolución causas y características del flujo migratorio (1882-1990), Alicante: Diputación Provincial de Alicante. Instituto de Cultura Juan Gil-Albert, 1995. 


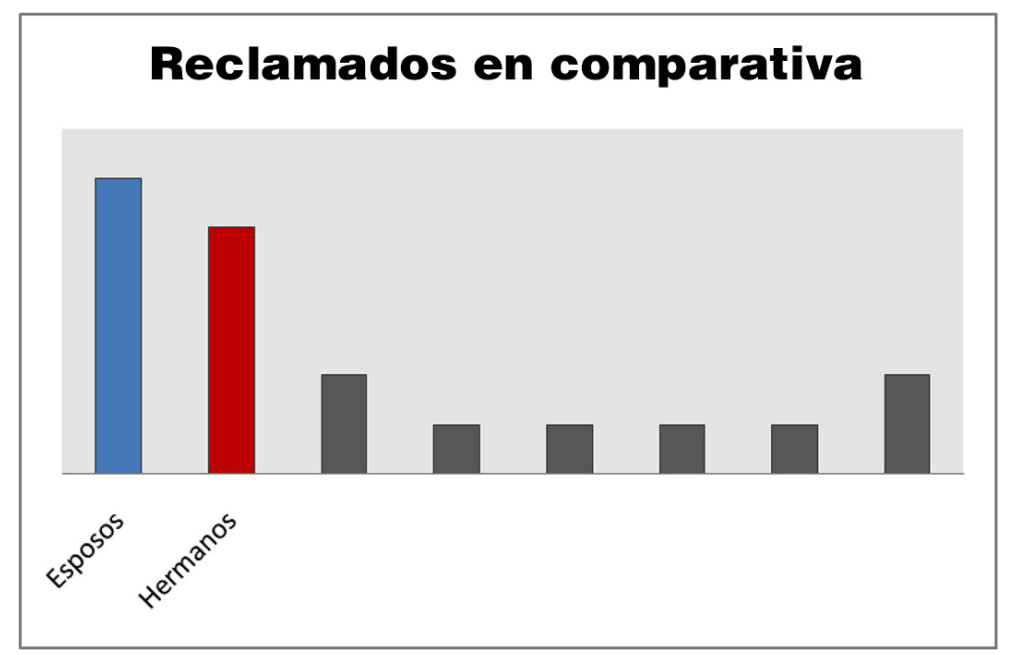

Figura 3. «Reclamados en comparativa». Elaboración propia.

Casi tres de cada cinco reclamaciones eran hechas por hermanos o cónyuges. $\mathrm{Si}$ se observa la figura 3, se puede ver que la diferencia entre las reclamaciones realizadas por el cónyuge o por los hermanos son las que más peso relativo tienen. Por un lado, destaca que una de cada tres cartas fue escrita para pedir información sobre sus esposos y/o esposas, aunque la mayoría sean sobre su esposo, y en segundo lugar, peticiones de información sobre hermanos o hermanas, en cuyo caso, la diferenciación por sexo no es tan acusada como en la tipología anterior. El resto de relaciones de parentesco son variadas y se pueden observar casos de cartas que fueron escritas por algún hijo, suegro, tío, vecino, etc., pero que no tienen un peso estadístico tan fuerte.

Hasta este momento, todas las ideas reflejadas en la documentación, con matizaciones, encajan dentro de lo que es el relato clásico de la emigración española a Venezuela, donde se produce una interesante variación de esa tónica generalizada es en el origen de los reclamantes.

Si se realiza una disección para conocer de dónde proceden las personas que reclaman información sobre sus parientes en Venezuela, el resultado es ciertamente llamativo, como muestra la figura 4. En cuanto a las zonas de origen, destacan dos cuestiones. Por un lado la heterogeneidad de lugares de procedencia, con muchos lugares de la geografía española representados, y, por otra parte, el porcentaje de reclamaciones que se hacen desde Madrid, las cuales representan unos números superiores a una de cada cuatro reclamaciones totales.

Además de ello, esta figura nos muestra varias cuestiones interesantes, por un lado la práctica ausencia de reclamaciones desde los principales territorios con afluencia masiva de emigrantes a Venezuela como son Canarias y Galicia, por ese 


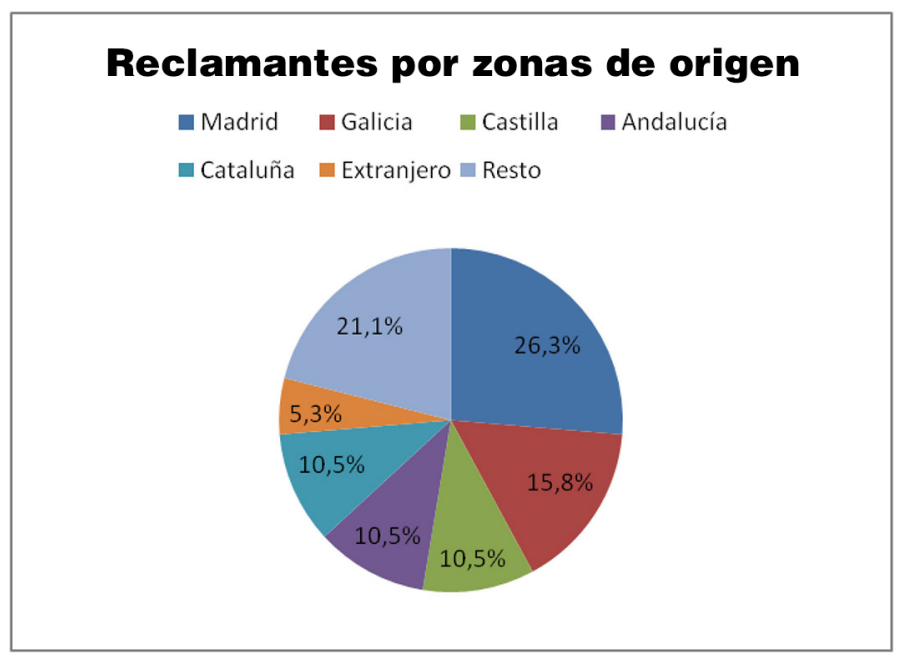

Figura 4. «Reclamantes por zona de origen». Elaboración propia.

orden $^{8}$. Realmente solo tenemos ese $15,8 \%$ de gallegos que no es representativo del contingente total (ni relativo) de gallegos que emigran a Venezuela en esta época. En el otro de los casos, las Islas Canarias, no aparece ni una sola referencia, lo cual es profundamente llamativo. Se puede inferir que ello es debido precisamente al alto porcentaje de emigrantes en Venezuela de estos territorios, lo cual permitía que las redes de información se construyeran de una forma más personal y sobre el terreno, y necesitaran menos de otros agentes como en este caso pueda ser la estructura diplomática del Estado. Así mismo, se puede inferir, que la sobrerrepresentación de otros territorios como Castilla y Extremadura, que, junto con Madrid, representan más de la mitad de las reclamaciones, puede obedecer a la cercanía a dicha estructura

${ }^{8}$ Para ver la importancia de los contingentes relativos por comunidades autónomas se recomienda una tabla presentada por Campos Álvarez en unos datos que reflejan los porcentajes de emigrantes emitidos hacia Venezuela a partir de 1965, pero que resulta totalmente extrapolable para períodos anteriores, puesto que están indisolublemente ligados. En esta tabla muestra que la suma de canarios y gallegos suponen más del $75 \%$ de los emigrantes españoles a Venezuela a partir de ese año. Además, no existen otros contingentes reseñables tras éstos. Véase Campos Álvarez, Xosé Ramón: «Centros gallegos en Venezuela», en Blanco Rodríguez, Juan Andrés: El asociacionismo en la emigración española a América, Salamanca: Junta de Castilla y León. UNED Zamora, 2008, p. 332. Para un repaso más profundo de la emigración canaria a Venezuela a mediados de siglo se recomienda Hernández González, Manuel: La emigración canaria a Venezuela, Santa Cruz de Tenerife, Las Palmas de Gran Canaria: Ediciones Idea, 2007, pp. 196-226. Para el caso de la gallega, se recomienda Campos Álvarez, Xosé Ramón: La emigración gallega a Venezuela, Madrid: tesis doctoral leída en la Universidad Complutense de Madrid, 2016. 


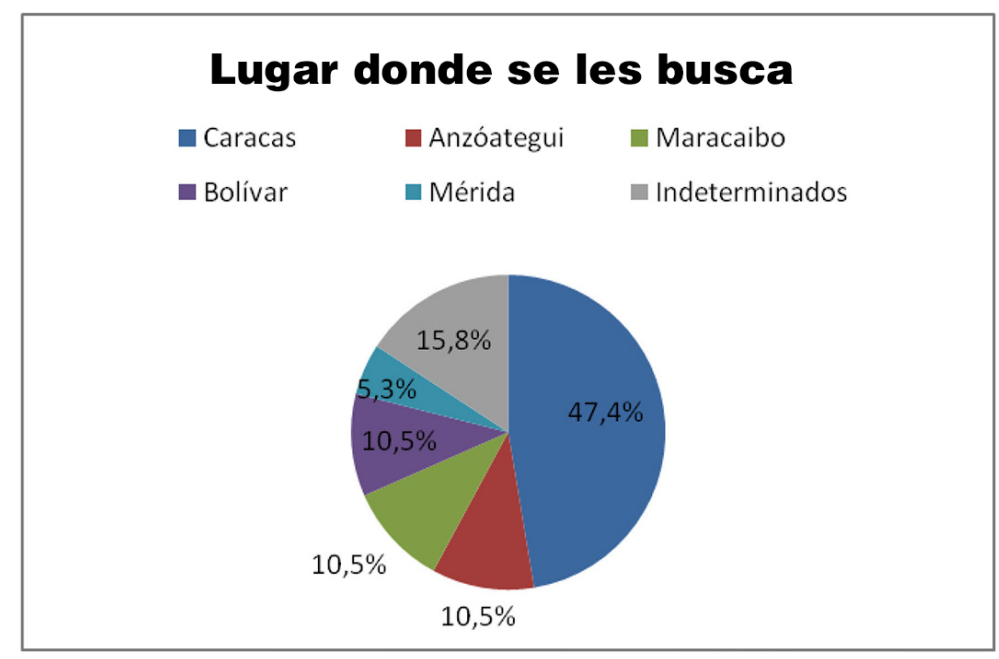

Figura 5. «Lugar donde se les busca». Elaboración propia.

del Estado, lo cual también ayudaría a explicar el alto porcentaje que muestra otra región como es Cataluña.

El último de los elementos a identificar es el lugar en el cual se les busca (figura 5), en el que presumiblemente se encuentran en Venezuela, que no es una cuestión carente de significado, pues termina por cuadrar el discurso en torno a esta documentación. Lo primero que podemos observar es una primacía absoluta de Caracas como lugar de recepción. Se puede inferir que ello es debido al carácter urbano de estos emigrantes, y al tipo de emigración basado en un goteo en lugar de un torrente ${ }^{9}$. Además, por simple realidad estadística Caracas contenía gran parte de la población del país ${ }^{10}$, hecho al cual había que sumarle que los principales puntos de entrada al país estaban cerca (como es el puerto de La Guaira) y que era una ciudad dinámica y en proceso de desarrollo.

$\mathrm{Al}$ alto elevado porcentaje que suma la ciudad de Caracas, uno de cada dos, habría también que sumarle las reclamaciones para Maracaibo, la segunda ciudad del país o las que se producen para las ciudades del estado Anzoátegui (lugar que alcanza un cierto desarrollo industrial). En definitiva, nos encontramos que para entorno rurales, solo hay un 5,5\% de reclamaciones (el correspondiente a Mérida),

9 En contrapartida con ello, los grupos más masivos, como es el caso de los canarios, se desplegarán por todo el país, véase Hernández González, Manuel: La emigración canaria a América, San Cristóbal de La Laguna: Gobierno de Canarias, Centro de la Cultura Popular Canaria, 2005, pp. 130-132.

${ }_{10}$ Siso Quintero, Gerardo José: «La población de Venezuela: evolución, crecimiento y distribución geográfica», en Revista Terra. Nueva etapa, vol, xxvıII, n. ${ }^{\circ}$ 43, 2012, p. 120. 
lo cual contrasta, por ejemplo, con el tipo de emigración que se da entre los canarios en esta misma época, con un mayor componente rural.

Antes de finalizar resulta necesario aclarar una cuestión que, probablemente, también es extrapolable a estos casos y que no es otra que la inestabilidad domiciliaria que el emigrante a Venezuela podía experimentar. Al funcionar la contratación laboral en una suerte de semiinformalidad, eso hacía que muchos emigrantes modificaran su lugar de residencia, generando dificultades (en unos casos de manera intencionada, en otros no) para que sus familias en origen pudieran contactar con ellos durante algún tiempo o de manera indefinida.

\section{HISTORIAR LA VIDA COTIDIANA A TRAVÉS DE ESTA CORRESPONDENCIA}

Además de un estudio cuantitativo que nos puede aportar datos significativos, como hemos visto anteriormente, la documentación histórica que hemos analizado nos permite adentrarnos en la realidad, en las vivencias personales que experimentaban las personas en un proceso de emigración. Es decir, tal y como decíamos en la introducción, nos permite historiar la vida cotidiana de las personas que vivieron esta emigración a Venezuela, ya sea como emigrante o como familiar que se quedaba en el lugar de origen del emigrante, y en el caso de estos familiares o conocidos ver cómo este proceso emigratorio les afectaba en su vida cotidiana de una forma u otra.

No es este el primer estudio historiográfico sobre documentación y misivas relacionado con la emigración a América ni a Venezuela. Se dan menos trabajos para la época y contexto en la que nos situamos en este artículo, pero existen ${ }^{11}$, mientras que para otros segmentos temporales y geográficos, los trabajos publicados son más profusos ${ }^{12}$.

Dentro del interés general que nos produce, hay varias secciones o bloques diferenciados a los que puede contribuir su estudio. Por ello, vamos a dividir en diferentes segmentos algunos ejemplos de casos, que nos pueden ofrecer datos con-

${ }^{11}$ Luis León, Ángel Dámaso; Martín Pérez, María Nazaret: «El Dorado tras el Atlántico: la imagen de Venezuela en Canarias a mediados del siglo XX», en Acosta Guerrero, Elena (coord.): XXII Coloquios de Historia Canario-americana, Las Palmas de Gran Canaria: Casa de Colón. Cabildo de Gran Canaria, 2017, pp. 3-6.

${ }^{12}$ Una buena muestra puede ser López Álvarez, Juaco: «Cartas desde América. La emigración de asturianos a través de la correspondencia», en Revista de dialectología y tradiciones populares, Tomo 55, Cuaderno 1, 2000, pp. 81-120; De Paz SÁnchez, Manuel: «"Al recibo de la presente...”. Algunas cartas personales de emigrantes canarios del siglo XIX", en Tebeto: Anuario del Archivo Histórico Insular de Fuerteventura, n. ${ }^{\circ}$ 15, 2002, pp. 493-505; NúŃEz SeIXAs, Xosé Manuel: «Otras miradas a la historia de la emigración gallega: sobre cartas, memorias y fotos», en Estudios Migratorios Latinoamericanos, vol. 19, n. ${ }^{\circ}$ 58, 2005, pp. 483-504; Arbelo García, Adolfo I.: Al recibo de esta... Relaciones epistolares canario-americanas del siglo XVIII, Santa Cruz de Tenerife, Las Palmas de Gran Canaria, 2010; Martínez Martín, Laura: Voces de la ausencia. Las cartas privadas de los emigrantes asturianos a América, Gijón: Editorial Trea, 2019. 
cretos de los emigrantes en Venezuela y/o cómo afecta dicho proceso migratorio al entorno en el lugar de origen.

\section{Oficios}

Tenemos algunos casos en los que a partir de los datos personales que se aportan para encontrar el paradero de la persona que buscan, podemos conocer las profesiones y/u oficios que desempeñan estos emigrantes en Venezuela. De estos datos podemos inferir, como hemos visto también anteriormente en el estudio cuantitativo, que son tareas destinadas a ser desarrolladas en el ámbito urbano. Sin embargo, estos oficios especificados son en todos los casos referentes los hombres, no hay ninguna referencia laboral de las mujeres emigrantes. También destaca que gran parte de los mismos suelen estar asociados a las clases medias.

Entre los oficios que podemos conocer se encuentran los siguientes:

- Negocio propio, taller de reparación de carrocerías de coches.

- Confitero.

- Topógrafo, especificando en qué lugar y con qué ingeniero trabaja.

- Oficial contable en el Banco Occidental de Descuento (en una sucursal situada en Maracaibo).

\section{MOTIVOS CONCRETOS PARA LA BÚSQUEDA}

En la gran mayoría de esta documentación, los emisores de las cartas buscan el paradero de sus familiares o conocidos debido a la ausencia de noticias; en todas ellas, por ese motivo se especifica el tiempo que hace que no reciben noticias de su familiar. Sin embargo, hay otros casos que, aunque relacionados, porque a fin de cuentas todos buscan a un familiar y/o conocido, el motivo que los lleva a buscar noticias es otro más concreto y significativo.

Algunos ejemplos de estos casos pueden ser los siguientes:

- Un hermano que intenta saber si los rumores que le han llegado sobre su hermano son ciertos, pues se dice que ha fallecido en un tiroteo en unos disturbios en Caracas.

- Un hijo que necesita un certificado firmado por el padre para poder ingresar voluntario a la Armada Aérea Espańola, y no da con su paradero, generándole la imposibilidad para poder entrar en la misma.

- Un vecino que intenta localizar a una vecina del mismo lugar de origen que había emigrado a Venezuela, para comunicarle el fallecimiento de un familiar, así como que ella forma parte de la herencia que le dejó dicho familiar. 


\section{GÉNERO Y EMIGRACIÓN}

Los casos de las mujeres que son reclamadas (y reclamantes) nos permiten acceder a ciertos conocimientos sobre la situación de las mismas, ya que estaban inmersas en el proceso migratorio, incluso sin "cruzar el charco» de manera física. No deja de ser relevante el hecho de que un proceso de emigración siempre afecta, ya sea de manera personal y/o social, a los dos territorios, el de origen y el de acogida, y su población.

En este apartado, se extractarán diferentes fragmentos de esta documentación relacionada con diversos afectos que pueden arrojar luz sobre la situación de estas mujeres. Se puede realizar una subdivisión de la casuística, ya que en los tres primeros fragmentos aparecen mujeres que son buscadas, mientras que en el resto son ellas las que demandan información sobre otras personas.

En cuanto a la transcripción de la presente correspondencia, se hará respetando al máximo la grafía, así como la ortografía original. Asimismo, todos los añadidos que se puedan realizar se recogerán en cursiva; por ejemplo, el concepto de firma autógrafa. Los nombres propios, serán representados con las iniciales, pues al tratarse de una documentación reciente y sensible, se ha intentado respetar el anonimato de estas personas. Por este motivo, también en las transcripciones hay fragmentos que no se han recogido, y que son señalizados con [...], ya que aportan datos personales o irrelevantes para nuestro objeto de estudio.

Madrid 23-9-60

Excmo Sr Embajada de Espańa en Venezuela

Despues de mucho pensarlo

y pidiendole mil perdones le ruego

y pido un pequeño favor y que para

mi es muy grande

En abril va hacer dos años que no tengo noticias de una hermana mia, y que tenia la residencia en Cara cas, Hotel Estacion, o Norte, asi creo se llama; tambien la escribia a este correo central, y sus cartas han sido devueltas, como desconocida. Temo la haya pasado algo, y acudo a la Embajada a la espera (si les es posible me den noticias de mi hermana, o hagan de decirla a ella que me las de para mi tranquilidad Dios guarde a su Exc muchos años Firma autógrafa 
En este documento ${ }^{13}$, se puede ver cómo una mujer busca a su hermana en su última dirección en Caracas, de la cual hace dos años que no tiene noticia. Tras el relato en su carta, se puede observar que se le olvida escribir el nombre de dicha hermana a la cual busca. En el documento original, se puede apreciar cómo el personal de la propia Embajada escribe en rojo sobre la carta [No dice como se llama su hermana], comentando este hecho.

En el siguiente documento ${ }^{14}$, no es un familiar el que busca a otro familiar, sino un habitante del mismo lugar de origen que la mujer emigrada. Este caso es significativo, porque nos da el dato de que la mujer a la que se busca emigró a los 68 años de edad, que para el año de 1960 sería extrapolable a una edad superior, debido al cambio experimentado en las últimas décadas en las condiciones de vida actuales.

Torrejoncillo 25 de Mayo de 1960

Exmo Sr. Embajador de Espańa en Venezuela

Caracas.

Excelentisimo Señor: -

Me permito molestar su atención por la pres sente para solicitar de esa Embajada de Espańa en Venezuela datos subre la subdita espańola $I . V$. $V$.de 72 años

natural de Torrejoncillos (Cáceres) viuda, que hace unos cuatro años que se marchó de Espańa con destino a ese pais, donde tenia dos hijos llamados Julian y Jesus que se habian marchado uno o dos ańos antes.

Se trata de comunicarle la muerte de un familiar ocurrido en este pueblo que la nombra heredera en unión de otros familiares. Yo la agradeceria que si en esa Embajada se conoce el paradero de la citada seńora o por medio de los Consulados de espańa puede V.E. averiguar el domicilio lo comunique a las señas que al dorso le detallo o si por desgracia hubiese fallecido y se pudiese recabar el justificante lo enviasen para poder tramitar la testamentaria.

Dandole las anticipadas y rogandole perdone las molestias que pudiera causarle en espera de sus noticias tengo el honor de quedar de V.E. seguro servidor.

Firma autógrafa

El caso que se presenta a continuación ${ }^{15}$ posee un matiz diferente, pues un ciudadano uruguayo, desde Montevideo se pone en contacto con la Embajada española para buscar a su esposa y sus tres hijos, situados en Venezuela, pues no sabe

13 Archivo General de la Administración (en adelante AGA), Fondo (10) 91.2, Signatura 54/11873. Carta manuscrita del 23 de septiembre de 1960.

${ }_{14}$ AGA, (10) 91.2, 54/11873. Carta mecanografiada del 25 de mayo de 1960, ff. 1-2.

15 AGA, (10) 91.2, 54/11873. Carta manuscrita del 13 de junio de 1960. 
nada de ellos desde hace un año. Este, además, hace referencia a su pasado militar, y a su lucha contra el comunismo.

Montevideo 13 de Junio de 1960

-Venezuela-

Respetable señor siento infitiba-

mente molestarlo en lo que le voy

a pedir tengo mi señora en esa

y hace más de un año que

no se noticias de ella y de

los hijos asi que me tengo

dirijir a usted por si

por mediación de de el consu-

lado español podia tener

noticias de ellos que asi lo

espero de mi más respetable

señor.

$[\ldots]$

tambien atendi a todos mis

superiores en la crusada

de Espańa e servido en la

82 division por liberación

de del comunismo.

$[\ldots]$

El siguiente documento presenta un caso delicado ${ }^{16}$, tal como el personal de la Embajada recoge en el margen superior de la propia carta. La misma es escrita por el padre de una joven casada por poderes con otro joven, el cual reside en Venezuela. Por tanto, es su suegro en nombre de su hija quien solicita que se averigüe el paradero de su yerno. Su hija había recibido una carta de otra joven desde Venezuela diciéndole que su esposo está en relación sentimental con ella y además está embarazada.

Logotipo o sello de la empresa

en la que trabaja el emisor

Confitería La Giralda

Almería 2 de noviembre de 1959

Excmo Sr. Embajador de España

Venezuela

$[\ldots]$

[...] El motivo de la presente, es que mi hija

$C$. de 22 años de edad contrajo matrimonio por

poderes con J.M.U., el dia 8 de mayo

${ }^{16}$ AGA, (10) 91.2, 54/11873. Carta manuscrita del 2 de noviembre de 1959. 
pasado, estando empleado en una confitería

denominada BURROUGHS, Puerto de la Cruz, Venezuela

[...]

Le enviaba periodicamente sus cartas, le arregló

la documentacion, envio en alguna ocasion dinero

se celebró la ceremonia, acompañé a mi hija a

Málaga, para que el Sr. médico la reconociese, y

solo esperar, un ultimo documento, para su embarque,

pero aqui aparece un buen dia, recibe carta de una

mujer que dice llamarse $T$. en la que dice, que el

marido de mi hija lo tiene ella, y que si no se puede ca-

sar, por la ceremonia, de hace unos meses, que dios

le mandará la bendición del cielo, con un hijo próximo a

venir.

Rogaria Excmo Sr. ya que por otros medios, no puedo

enterarme, acudo a la amabilidad de V.E., por si

pudiese mandar una información, lo mas comple-

ta posible, sobre este asunto, para saber a que atener-

me y obrar en consecuencia, sobre el matrimonio de

mi hija.

$[\ldots]$

Firma autógrafa

En el siguiente documento ${ }^{17}$, es un religioso quien pregunta en nombre de una mujer por su novio. El interlocutor quiere conocer sus intenciones con ella y recomienda que la búsqueda sea en secreto.

Logotipo o sello del Colegio Internado

«Beato Francisco Gálvez» Utiel 25 de mayo de 1960

$[\ldots]$

Del mencionado joven, $A . T . A$., tanto

sus padres como una joven que sostiene relaciones hace ya años

con él, no tienen noticias suyas desde hace más de dos meses.

Esta joven me suplica mire la forma de obtener noticia

sobre su pretendiente, y es por lo que, confiando, en su ama-

bilidad y bondad, tengo el atrevimiento de dirigirme a su Exci

Iltma. Para ver de solucionarnos estas dudas:

$1^{\text {a }) ~ ¿ E s t a ́ ~ e n f e r m o ~ o ~ a c c i d e n t a d o ~ d i c h o ~ j o v e n ? ~}$

2a) Su comportamiento moral y patriótico, ¿ofrece garan-

tias de espera a la mencionada joven?

${ }_{17}$ AGA, (10) 91.2, 54/11873. Carta mecanografiada del 25 de mayo de 1960. 
Desearía que el procedimiento fuese secreto y sin que

él llegara a sospechar nada, como también recibieremos con sumo gusto cuantas informaciones pueda su Excia. transmitirnos y que, en su valioso parecer, crea debamos conocer.

$[\ldots]$

Vemos un caso en el que una esposa necesita saber si su esposo ha fallecido o no, para poder asociarse al servicio doméstico y, tal como ella misma escribe en su carta, poder tener un porvenir ${ }^{18}$.

Mis señas son S.G.A.

Madrid. [...]

Le adjunto esta nota sola mente para

de cirle que no me importa saber el para

dero de mi marido por que como el me

abandono pero si una nota para llo

poder asociarme al servicio domestico y

pa eso necesito la nota para saber si mi

marido es muerto o bibe para llo arregal

eso y tener un por benir el Dia mañana

asi aga favor de contestarme parto con

lo que uste le paresca fallecido o desapareci

do

$[\ldots]$

En el siguiente documento ${ }^{19}$, se puede observar a una mujer que busca a su esposo. En la carta comenta que ya lo había buscado a través de la Embajada con anterioridad para que se hiciera responsable del sustento económico de su familia, pues ella sola no puede cubrir todas las necesidades de sus cuatro hijos.

Fermoselle 25-12- 59

Sr. Embajador Español en Venezuela

Me dirijo a Vd pidiendole de ante-

mano favor y perdón si le falto a $\mathrm{Vd}$ en

algo al escribirle por ser una analfabeta

le ruego que mi marido hace 4 años se

marcho a esa y dese luego me ha escrito

muy pocas veces ya $\mathrm{Vd}$. lo busco una vez

y ahora llevo desde el mes de Agosto no

ha vuelto a saber nada de el me encuentro

con cuatro hijos de posición el dia y la no-

${ }_{18}$ AGA, (10) 91.2, 54/11873. Carta manuscrita. Sin fecha conocida.

19 AGA, (10) 91.2, 54/11873. Carta manuscrita del 25 de diciembre de 1959. 
che criandoles con el sudor de mi frente trabajando en el campo como una esclava por no ocuparse mi marido de mi. Asi que le ruego comunique su paradero. Yo le confieso a Vd. que no se que va a ser de mi vida y de mis cuatro hijitos.

$[\ldots]$

Por último, en este documento ${ }^{20}$ podemos conocer el caso de una mujer que, debido a que atraviesa por situaciones adversas, le había dado autorización a una familia conocida por ella y que iba a emigrar a Venezuela para que se llevara con ellos a su hija de tres años de edad. Esto había acontecido ocho años atrás; sin embargo, su situación económica había mejorado desde entonces, y desea que su hija vuelva con ella; sin embargo, hace dos años que no tiene noticia de su hija ni de dicha familia.

Barcelona 16 Febrero 1960

Excelentisimo Sr. Embajador de España en Venezuela:

Me dirijo a Vd. en espera de su amabilidad

me pueda atender en lo que acontinuación le expongo.

En el año 1951 salieron de España hacia

Venezuela, una familia los cuales llevaban junto con

ellos una hija mia de tres ańos con mi autorizacion;

Al principio, algunas noticias indirectamente recibí

dándome a conocer que habian llegado bien y se desem-

volvian con regularidad y que mi hija estaba bien.

Por razones que me heran adversas no podia hacer otra

cosa, sino conformarme así. Debido a que más tarde

me case, por lo cual mi situacion ha cambiado, y

estando en condiciones de poderla tener conmigo, si

las circunstancias de ellos no les fueran favorables.

Haciendo más de dos años que no sabemos

nada lo mismo sus familiares de aquí en España que yo,

$\mathrm{y}$, habiendo intentado por todos los medios y no recibiendo

ninguna contestación, es por lo que me atrevo a moles-

tarle, abusando de su amabilidad y rogandole me perdone

el atrevimiento, le suplico me conteste, dandome razón

de como y donde viven y cómo se encuentra mi hija.

$[\ldots]$

${ }^{20}$ AGA, (10) 91.2, 54/11873. Carta mecanografiada del 16 de febrero de 1960. 


\section{CONCLUSIONES}

En este artículo, se ha podido evidenciar cómo a través del análisis y estudio de esta documentación de carácter epistolar se puede historiar la emigración, la vida cotidiana y las implicaciones familiares y sociales que el proceso migratorio puede ocasionar en ambas realidades, tanto en las regiones originarias como en el lugar de acogida.

En cuanto a esta documentación en concreto, se puede inferir que este tipo de emigración que no se produce de forma masiva sino "por goteo» (a diferencia de Canarias y Galicia), y que no tiene unas redes interpersonales tan importantes, como resultado de dicha emigración "por goteo», necesita de otras redes de carácter más institucional para obtener información de sus allegados. Hay que tener en cuenta que en esta documentación los protagonistas son el común de la población, que se encuentran ante la situación de no tener otra opción para este fin más que recurrir a la legación diplomática estatal. Por el contrario, como en el caso de Canarias y Galicia, la emigración masiva genera que el elemento o canal de comunicación sea mayormente familiares o amigos que son del mismo lugar de origen y que conocen o pueden conocer el paradero de este familiar al que buscan. Por tanto, se pueden evidenciar dos tipos de relaciones interpersonales, como resultado o relacionado con el tipo de emigración que se dé, ya sea masiva o "por goteo», como es el caso de la documentación en cuestión. Por ello, en esta documentación, nos encontramos con un bajo (Galicia) o nulo (Canarias) porcentaje de representación para estas comunidades.

Por último, cabe destacar que en este artículo se cumple la premisa que se recogía en la introducción del presente trabajo, que no ha sido otra que poner en valor este tipo de documentación, y cómo a través de la misma podemos conocer desde una perspectiva más íntima la historia de nuestro pasado más reciente. 
